\title{
Aerodynamic Analysis of the Multichannel Air Cleaning Equipment with curvilinear channels
}

\author{
Pranas Baltrènas, Diana Platova, Albertas Venslovas \\ Department of Environmental Protection, Vilnius Gediminas technical University, \\ Sauletekio ave. 11, LT-10223, Vilnius, Lithuania
}

\begin{abstract}
The aim of experimental tests is to determine aerodynamic characteristics in an improved multichannel cyclone with a spiral shell. This device was developed in order to improve the separation of ultra-fine solid particles from a polluted air (gas) flow. The purification device was designed at the Department of Environmental Protection (DEP) of Vilnius Gediminas Technical University (VGTU). Since the quality of air (gas) flow cleaning process is largely dependent on aerodynamic characteristics (air flow velocity and device's resistance), air (gas) flow velocity in a multichannel cyclone with a spiral shell and the overall resistance of the cyclone device depending on the number of channels and the positioning of curvilinear semi-rings were determined during experimental tests.
\end{abstract}

Keywords: Cyclone; spiral shell; channel; air (gas) flow.

\section{Nomenclature}

$\Delta \mathrm{D}_{\mathrm{f}} \quad$ dispersion composition of particulate matter

\section{Introduction}

A rapid growth of the global economy, heavy traffic flows, developing industries and energy are responsible for increasingly growing pollutant emissions. Atmospheric pollution with particulate matter remains one of the key factors not only contributing to global climate change but also affecting the quality of human life, particularly when an increased concentration of minute solid particles $\left(\Delta \mathrm{D}_{\mathrm{f}}<10 \mu \mathrm{m}\right)$ in the ambient air results from certain climatic factors which prevent the dispersion of released pollutants and dust from poorly cleaned streets $[6 ; 7]$.

In order to resolve problems posed by fine solid particles, increasingly stringent environmental protection requirements are set in respect of industrial and energy facilities emitting particulate matter. Removal of particulate matter from industrial air (gas) flows using air purifiers of different structures has particularly gained in importance $[8 ; 14 ; 11]$.

Cyclones of different structures have been used to clean polluted air (gas) flows discharged by industrial and production facilities for more than a hundred years. These air cleaning devices can achieve a high level of purification, particularly as regards the removal of solid particles of larger fractions. Air (gas) flow cleaning in cyclones is based on the operation of centrifugal forces. Typically, these devices are of two different structures - air (gas) flow is supplied in the tangential or in the axial direction $[10 ; 9]$.

An air purification device - an old-generation cyclone - consists of a shell, a particulate matter accumulation hopper, and air inlet and outlet ducts. These devices boast a number of advantages: they are nearly the only air purifiers that can remove solid particles from air (gas) flow even at high temperatures (up to $500{ }^{\circ} \mathrm{C}$ ), and are compact and easy to operate. Disadvantages of cyclones: a sharp drop in cleaning efficiency in the presence of leakage, higher energy costs and a fall in pressure at higher incoming flow velocities, and also an insufficient level of air flow cleaning, particularly when it is polluted with fine $\left(\Delta \mathrm{D}_{\mathrm{f}}<10 \mu \mathrm{m}\right)$ solid particles $[2 ; 4 ; 12]$.

The particularity of a new-generation cyclone lies in the fact that it uses curvilinear semi-rings for additional air filtration. A polluted air (gas) flow in the new-generation cyclones is cleaned by filtration through several layers of return

Corresponding author: Albertas Venslovas. E-mail address: albertas.venslovas@vgtu.lt

http://dx.doi.org/10.3846/enviro.2014.004

(C) 2014 The Authors. Published by VGTU Press. This is an open-access article distributed under the terms of the Creative Commons Attribution License, which permits unrestricted use, distribution, and reproduction in any medium, provided the original author and source are credited. 
air (gas) flow. The change of spaces between curvilinear semi-rings helps adjust and determine the optimum air (gas) flow rate accessing the transit and peripheral channels, thus regulating the course of air (gas) flow cleaning process.

Velocity and movement trajectory of an air (gas) flow being cleaned and also the overall resistance of cyclone unit provide considerable knowledge about the distribution of particulate matter within the curvilinear air (gas) flow, which allows us to evaluate the filtration capacities of an air cleaning unit, while this shows that the character of a flow is very important $[10,1,13]$.

While carrying our cyclone design works and gaining knowledge about the operational principle of cyclones a number of assumptions can be made. Modern simulation programmes require a very large amount of data about cyclone characteristics. Results obtained during experimental tests are used to improve the technical parameters of cyclones (e.g. to achieve the best minimum aerodynamic resistance/maximum air (gas) flow cleaning efficiency ratio) [3; 5; 14].

The aim of the work is to analyse and compare the aerodynamic characteristics of a multichannel cyclone with a spiral shell depending on the number of channels and the positioning of curvilinear semi-rings inside the cyclone structure.

\section{Methodology}

Experimental tests aimed at determining aerodynamic parameters were carried out with an improved multichannel cyclone with a spiral shell which is installed at the Environmental Protection Technologies Laboratory of Vilnius Gediminas Technical University (VGTU EPTL). An experimental stand of the multichannel cyclone with a spiral shell is presented in Figure a. The cyclone of the aforementioned structure is adapted for removing ultra-fine $\left(\Delta \mathrm{D}_{\mathrm{f}} \leq 10 \mu \mathrm{m}\right)$ solid particles from an air (gas) flow.

With the help of the axial ventilator Dospel WK 100 (70 W capacity) ambient air is supplied via the inlet air (gas) flow duct (4) $(75 \mathrm{~mm})$ to the separation chamber (1) where solid particles are precipitated, under the impact of centrifugal forces, via segment spaces from the separation chamber to the hopper (2) in which they are accumulated. Cleaned air is released from the system via the air (gas) flow outlet and travels to the outlet air (gas) flow duct $(75 \mathrm{~mm}$ ).

To measure air (gas) flow velocity, special slots were made in the cyclone for measuring air (gas) flow velocity in the respective points of each channel of the multichannel cyclone with the help of a Pitot-Prandtl tube. In order to minimise the average error of obtained measurement results, measurements of air (gas) flow velocity in the channel points are performed nine times (three times in the peripheral layer by the wall, in the middle of the cross-section of each channel and by the internal wall of the channel).

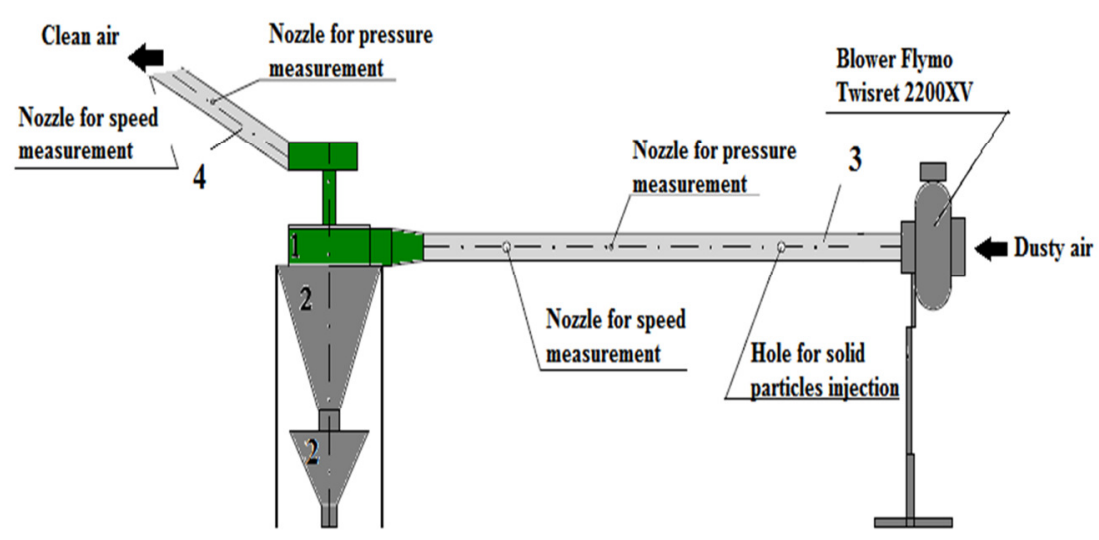

(a)

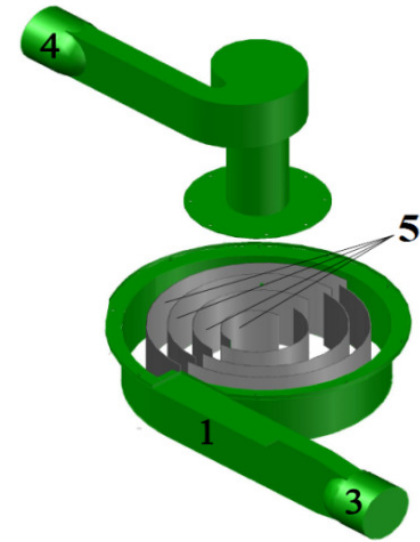

(b)

Fig. 1. Experimental stand of multichannel spirals-hell cyclone (a) and internal structure of the multichannel cyclone with a spiral shell (b): 1 - multichannel cyclone with a spiral shell; 2 - double hopper; 3 - air (gas) flow inlet; 4 - air (gas) flow outlet; 5 - curvilinear semi-rings

The dynamic resistance of a multichannel cyclone with a spiral shell is determined by measuring air pressure in the air inlet (4) and outlet (3) ducts upon connecting the differential pressure meter DSM-1 (measurement range 0-20000 kPa; error $\pm 5 \mathrm{~Pa}$ ) by hoses to special nozzles fitted up for pressure measurements by the inlet and outlet air ducts. This parameter shows what pressure loss is incurred after an air (gas) flow has passed through all channels of the multichannel spiral cyclone. In order to avoid systematic and random errors in dynamic resistance measurements, each measurement is repeated three times.

Instruments used during experimental tests:

1. Multifunctional meter TESTO-452;

2. Pitot-Prandl tube;

3. Pitot-Prandl tube and multifunctional TESTO-452 meter connector;

4. Differential pressure meter DSM-1.

Experiments on aerodynamic characteristics were conducted using four-, six- and eight-channel spiral cyclones with 3,5 and 7 curvilinear semi-rings of different radii, respectively. Three different internal structures of cyclones were tested in 
each case by changing spaces between curvilinear semi-rings of different radii, i.e. by changing their positions and thus changing peripheral/transit air (gas) flows ratios. Selected positions: 25/75 - the volume of peripheral (return) air (gas) flow is $25 \%$ lower than that of transit air (gas) flow (running to the next channel); $50 / 50$ - equal distribution of air (gas) flow volumes; $75 / 25$ - volume of peripheral air (gas) flow is $25 \%$ lower than that of transit one. The spiral cyclone's internal structure is shown in Fig. b.

In the separation chamber, an air (gas) flow first enters the first cyclone channel (I), afterward it is filtrated through different spaces among semi-rings $(25 / 75 ; 50 / 50$ or $75 / 25)$ where the respective part of air (gas) flow enters the previous channel (peripheral) and the other - the next (transit) channel. Such air (gas) flow distribution takes place at the end of each channel. Under the impact of centrifugal forces particulate matter is pushed towards the peripheral channel's wall and via segment slots falls into the hopper where it is accumulated. The part of the air (gas) flow that has passed through all channels of a spiral cyclone is removed from the system via an air (gas) flow outlet duct. The part of the air (gas) flow entering the peripheral channel creates a "curtain" against inflowing dusty air. This air (gas) flow curtain helps to additionally filtrate ultra-fine solid particles $\left(\Delta \mathrm{D}_{\mathrm{f}}<20 \mu \mathrm{m}\right)$ from the dusty air. Such filtration significantly increases the purification efficiency of a cyclone device. The air (gas) flow cleaned in the same manner passes through all channels and is discharged via the air flow outlet.

Experimental tests on air (gas) flow velocity were carried out on the basis of the Methodology for the measurement of gas flow velocity and volume rate LAND 27-98/M-07. Measurements were conducted using the Pitot-Prandtl tube connected to the multifunctional meter TESTO 452.

\section{3. Results and discussion}

Experimental measurements of air (gas) flow movement velocity in the channels of the multichannel spiral cyclone were conducted by arranging measurement points so as to ensure that the change of air (gas) flow velocity in each channel is viewable. Air (gas) flow velocities were measured in five points of each cyclone channel. Data obtained during experimental measurements are presented in the form of velocity charts and tables so as to show the velocity average in each measurement point.

Table 1 shows the average values of recorded air (gas) flow velocities in each measurement point. Measurements were carried out for four-, six- and eight-channel spiral cyclones. In the case at issue the overall air (gas) flow volume distributes at a ratio of $75 / 25$, i.e. $75 \%$ of the total air (gas) flow discharge travels to the peripheral channel, while the remaining $25 \%$ portion - to the transit channel.

Table 1. Air (gas) flow velocity distribution in the multichannel cyclone channels when air (gas) flow distribution ratio stands at 75/25

\begin{tabular}{|c|c|c|c|c|c|c|}
\hline \multicolumn{6}{|c|}{4 channels, $75 / 25$} & \multirow{2}{*}{ Average } \\
\hline & 1 & 2 & 3 & 4 & 5 & \\
\hline 1 channel & 5.6 & 5.3 & 5.6 & 5.9 & 5.0 & 5.5 \\
\hline 2 channel & 5.4 & 5.2 & 5.2 & 5.3 & 5.4 & 5.3 \\
\hline 3 channel & 5.2 & 5.2 & 5.2 & 5.1 & 5.3 & 5.2 \\
\hline 4 channel & 5.2 & 5.1 & 5.3 & 5.3 & 5.4 & 5.3 \\
\hline \multicolumn{6}{|c|}{6 channels, $75 / 25$} & Average \\
\hline & 1 & 2 & 3 & 4 & 5 & \\
\hline 1 channel & 4.7 & 4.6 & 4.4 & 4.5 & 4.6 & 4.6 \\
\hline 2 channel & 4.2 & 4.5 & 4.8 & 4.2 & 4.4 & 4.4 \\
\hline 3 channel & 4.4 & 4.6 & 4.8 & 4.4 & 4.2 & 4.5 \\
\hline 4 channel & 4.2 & 4.8 & 4.5 & 4.4 & 4.4 & 4.5 \\
\hline 5 channel & 4.4 & 4.5 & 4.5 & 4.1 & 4.5 & 4.4 \\
\hline 6 channel & 4.7 & 4.8 & 4.5 & 4.3 & 4.1 & 4.5 \\
\hline \multicolumn{6}{|c|}{8 channels, $75 / 25$} & Average \\
\hline & 1 & 2 & 3 & 4 & 5 & \\
\hline 1 channel & 3.8 & 3.7 & 3.8 & 3.7 & 3.6 & 3.7 \\
\hline 2 channel & 3.4 & 3.4 & 3.5 & 3.6 & 3.5 & 3.5 \\
\hline 3 channel & 3.4 & 3.5 & 3.5 & 3.2 & 3.4 & 3.4 \\
\hline 4 channel & 3.5 & 3.5 & 3.4 & 3.2 & 3.4 & 3.4 \\
\hline 5 channel & 3.4 & 3.4 & 3.6 & 3.5 & 3.7 & 3.5 \\
\hline 6 channel & 3.5 & 3.5 & 3.7 & 3.6 & 3.6 & 3.6 \\
\hline 7 channel & 3.1 & 3.0 & 3.1 & 3.1 & 3.6 & 3.2 \\
\hline 8 channel & 3.6 & 3.6 & 3.7 & 3.7 & 3.6 & 3.6 \\
\hline
\end{tabular}


In the case of a four-channel cyclone the maximum air (gas) flow velocity was recorded in Channel 1 where its average value reaches $5.5 \mathrm{~m} / \mathrm{s}$. In the case of a six-channel structure the maximum air (gas) flow velocity of $4.6 \mathrm{~m} / \mathrm{s}$ was determined in Channel 1. The highest value of air (gas) flow velocity in eight-channel cyclone $-3.7 \mathrm{~m} / \mathrm{s}-$ was also found in Channel 1 . This leads to the conclusion that the maximum air (gas) flow velocity in all analysed cases was determined in the first channel of a spiral cyclone regardless of the number of curvilinear channels. It has also been noticed that the average value of air (gas) flow velocity in a six-channel cyclone is $20 \%$ lower than in a four-channel cyclone. In the case of an eightchannel cyclone the value of velocity falls by around $49 \%$. It has been determined that a double increase in the number of channels reduces airflow velocity in the first channel by half.

Minimal air (gas) flow velocities were recorded in spiral cyclone's Channel $3(5.2 \mathrm{~m} / \mathrm{s})$ during tests with a four-channel spiral cyclone. In the case of a six-channel spiral cyclone the lowest velocities were in Channels 2 and 5 (4.4 m/s), while in the case of an eight-channel cyclone - in Channel $7(3.2 \mathrm{~m} / \mathrm{s})$. It follows from the results of experimental tests that in the case of minimum air (gas) flow movement there remains a tendency that an increasing number of channels proportionally decreases air (gas) flow velocity showing a nearly $40 \%$ drop between four- and eight-channel cyclone structures.

Another observed tendency - when an air (gas) flow is approaching the cyclone's axis its velocity increases compared to velocities in the previous channels, and in the last channel air (gas) flow velocity is only by $0.1 \mathrm{~m} / \mathrm{s}$ lower than in the first channel.

Figure 2 presents a diagrammatic representation of air (gas) flow velocities within cyclone channels in the case of a fourchannel structure. The diagram shows that air (gas) flow velocity insignificantly changes in all channels because of a changing cross-sectional area of the channels. Velocity increases when an air (gas) flow is approaching the cyclone's axis. Average velocity in the first channel reaches $5.5 \mathrm{~m} / \mathrm{s}$, in the second $-5.3 \mathrm{~m} / \mathrm{s}$ (a $3.7 \%$ decrease), in the third $-5.2 \mathrm{~m} / \mathrm{s}$ (a $1.9 \%$ decrease), and in the fourth $-5.3 \mathrm{~m} / \mathrm{s}$ (a 1.9\% increase). Overall decrease in air (gas) flow velocity inside the cyclone structure represents $3.7 \%$.

Figure 3 presents a diagrammatic representation of air (gas) flow velocities within cyclone channels in the case of a sixchannel structure. Data presented in the chart show that the average velocity in Channel 1 reaches $4.6 \mathrm{~m} / \mathrm{s}$ (19.6\% lower

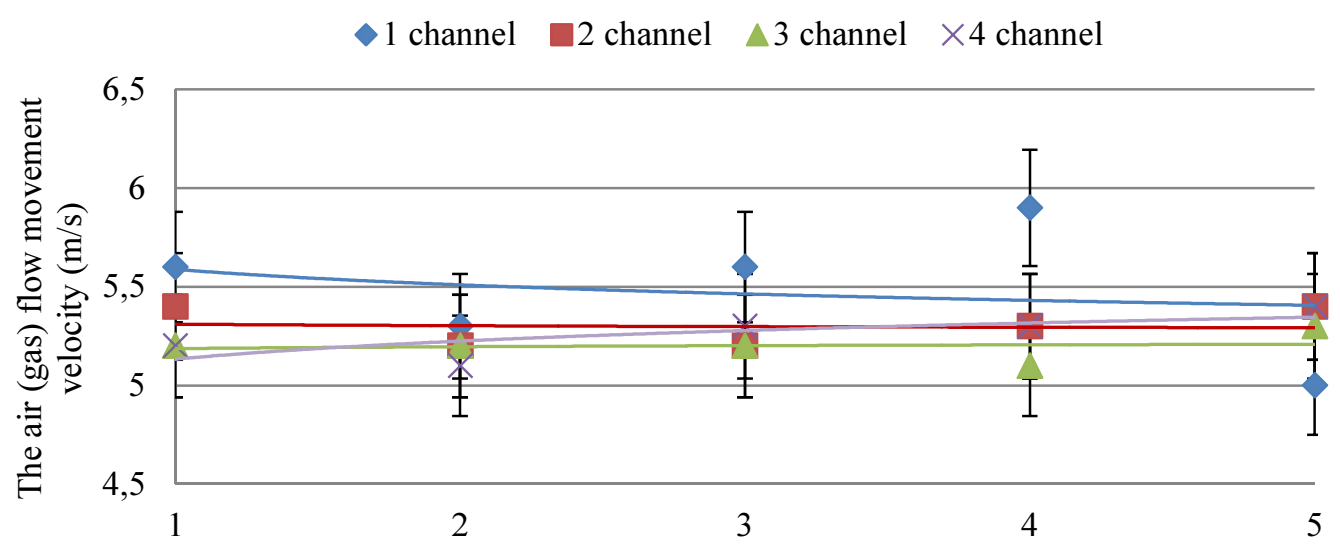

The air (gas) flow velocity measure points in the channels of the spiral cyclone

Fig. 2. Air (gas) flow velocity distribution within four-channel spiral cyclone channels when curvilinear semi-rings are positioned at $75 / 25$

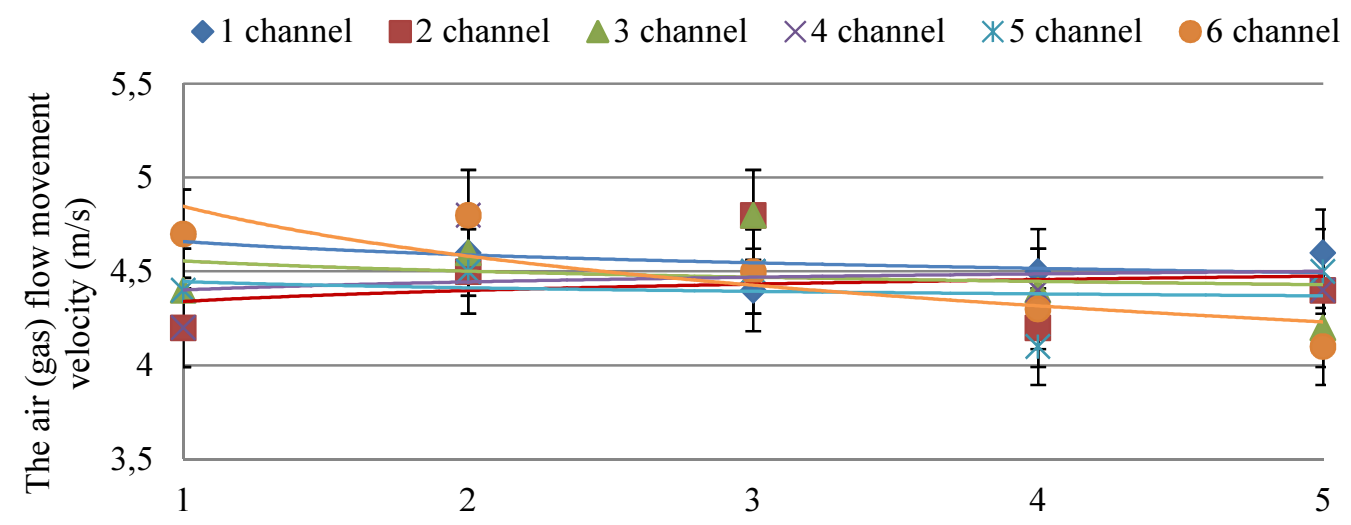

The air (gas) flow velocity measure points in the channels of the spiral cyclone

Fig. 3. Air (gas) flow velocity distribution within six-channel spiral cyclone channels when curvilinear semi-rings are arranged in $75 / 25$ position 
than in the case of four channels), in Channel $2-4.4 \mathrm{~m} / \mathrm{s}(20.4 \%$ lower than in the case of a four-channel structure $)$, in Channel $3-4.5 \mathrm{~m} / \mathrm{s}(15.6 \%$ lower than in the case of four channels), and in Channel $4-4.5 \mathrm{~m} / \mathrm{s}$ (17.8\% lower compared to four channels). It has been determined from the comparison of four- and six-channel structures that air (gas) flow velocity in the case of six channels (two additional channels) drops, on average, by $18 \%$ under the impact of resistance forces.

Figure 4 shows a diagram of air (gas) flow velocities within cyclone channels in the case of an eight-channel structure. As data given in Fig. 5 show, the average velocity in the first channel reaches $3.7 \mathrm{~m} / \mathrm{s}(48.6 \%$ lower than in the case of four channels and $24.3 \%$ lower compared to six channels $)$, in the second $-3.5 \mathrm{~m} / \mathrm{s}(51.4 \%$ lower than in the case of four channels and $25.7 \%$ lower compared to six channels), in the third $-3.4 \mathrm{~m} / \mathrm{s}(52.9 \%$ lower than in four channels and $32.4 \%$ lower than in six channels), and in the fourth $-3.4 \mathrm{~m} / \mathrm{s}(55.9 \%$ lower than in the case of four channels and $32.4 \%$ lower compared to six channels). It follows from the performed comparison of four-, six- and eight-channel spiral cyclone structures that under the impact of resistance forces air (gas) flow velocity in an eight-channel structure, on the average, falls by 52\%, compared to a four-channel cyclone, and drops by $29 \%$, compared to a six-channel cyclone.

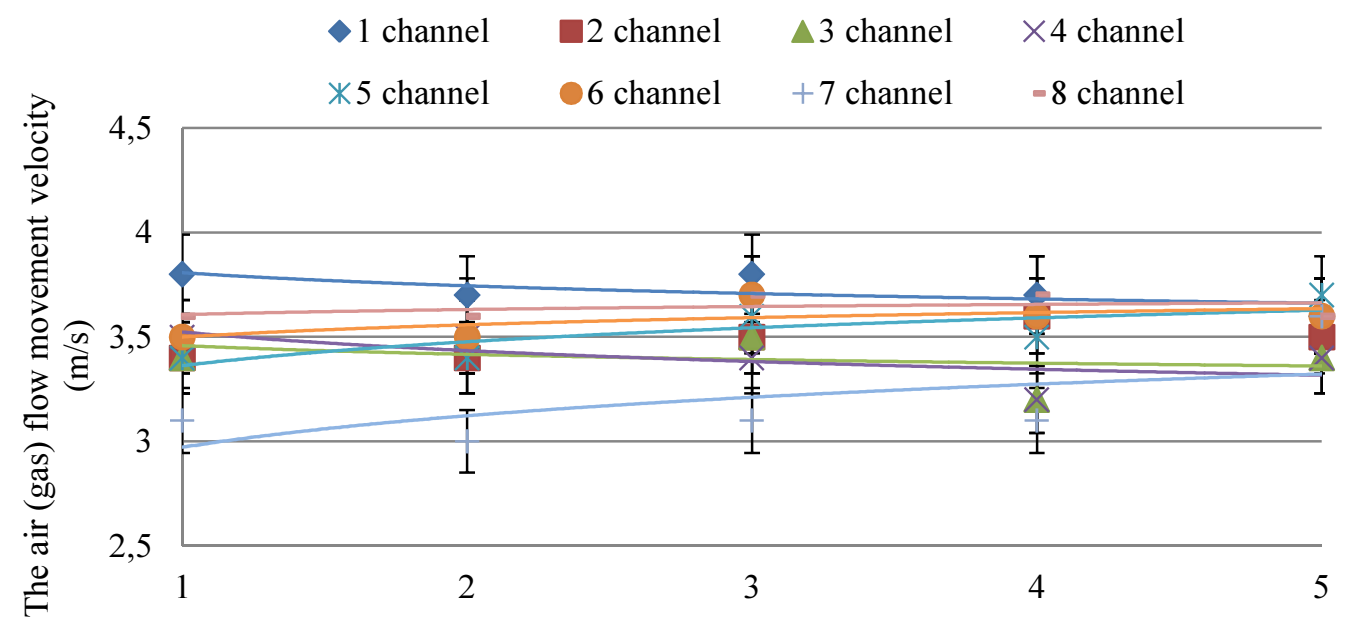

The air (gas) flow velocity measure points in the channels of the spiral cyclone

Fig. 4. Air (gas) flow velocity distribution within eight-channel spiral cyclone channels when curvilinear semi-rings are arranged in $75 / 25$ position

When curvilinear semi-rings are arranged in $75 / 25$ position, i.e. when $75 \%$ of the air (gas) flow rate is directed to the peripheral channel, and $25 \%$ - to the transit one, relatively high aerodynamic resistance is created leading to uneven distribution of air (gas) flow velocity within spiral cyclone channels. The comparison of experimental test results when $3 / 4$ of the air (gas) flow rate is directed to the peripheral channel shows that in the case of four-, six- and eight-channel structure of a spiral cyclone air (gas) flow velocities become particularly uneven due to the formation of an air (gas) flow "curtain" in the peripheral channel. For this reason air (gas) flow velocity yet more drops as a transit air (gas) flow is blocked when big obstacles are created and the axial ventilator fails to ensure the required air (gas) flow velocity.

The performed evaluation of the impact of the number of channels in a multichannel spiral-shell cyclone on air (gas) flow velocity has shown that an increase in the number of channels leads to a proportional decrease in air (gas) flow velocity inside cyclone structure. The average velocity of an air (gas) flow determined inside cyclone structure in the presence of four channels is $5.3 \mathrm{~m} / \mathrm{s}$, in the case of six channels $-4.5 \mathrm{~m} / \mathrm{s}$, and in the case of eight channels $-3.5 \mathrm{~m} / \mathrm{s}$. It is apparent that the addition of two channels results in an $18 \%$ drop in air (gas) flow velocity and the addition of four channels - a $51 \%$ fall.

It follows from the above that due to more active resistance forces inside the cyclone leading to a significant change in air (gas) flow velocity pressure produced by the axial ventilator is insufficient and does not ensure the required air (gas) flow velocity within all multichannel cyclone channels. Insignificant deviations can also be determined by the ventilator of the exhaust system connected to the cyclone stand concerned which creates low air extraction.

The irregularity of air (gas) flow velocity is based on the cross-sectional area of changing channels, which leads to irregular air (gas) flow rate in the respective measurement points. The peculiarities of the spiral cyclone structure produce differences in air (gas) flow velocity.

The resistance of a multichannel cyclone with a spiral shell was determined by measuring air pressure in air inlet and outlet ducts upon connecting the differential pressure meter DSM-1 (error $\pm 5 \%$ ).

Based on the data of experiments with four-, six- and eight-channel spiral cyclones it has been determined that the lowest resistance of the device, $238 \mathrm{~Pa}$, is in the case of a four-channel cyclone, a six-channel cyclone develops $286 \mathrm{~Pa}$ resistance and eight channels have a resistance of $310 \mathrm{~Pa}$ (Fig. 5).

Compared to a four-channel cyclone, six-channel spiral cyclone develops $48 \mathrm{~Pa}$ or $17 \%$ higher aerodynamic resistance. Aerodynamic resistance in an eight-channel cyclone structure grows by $72 \mathrm{~Pa}$ and $24 \mathrm{~Pa}$ compared to four- and six-channel cyclones, respectively. 


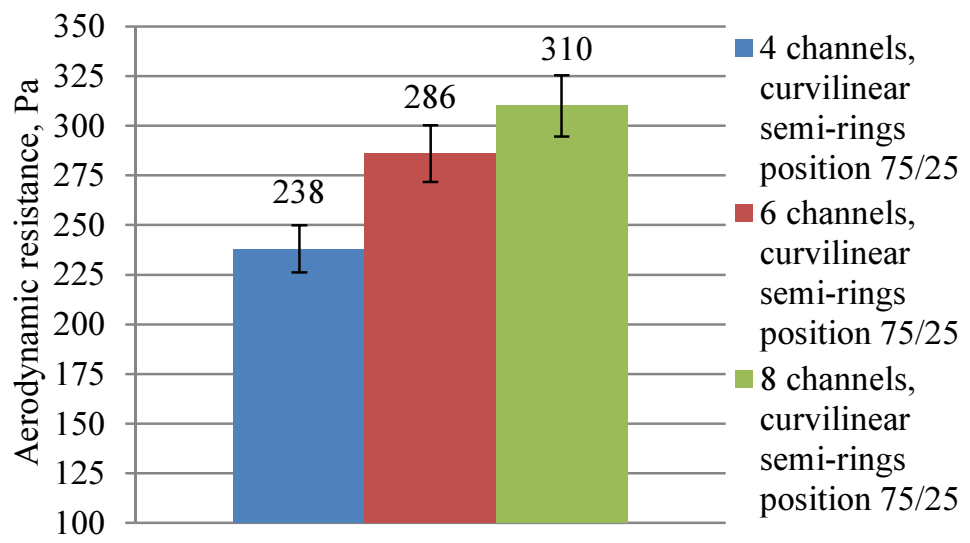

Fig. 5. The resistance of a multichannel spiral cyclone when air (gas) flow distribution ratio stands at $75 / 25$

It has been noticed that, like in the case of air (gas) flow movement, aerodynamic resistance changes depending on the number of spiral cyclone channels. It has been established that when the number of channels increases the aerodynamic resistance of a cyclone device also respectively increases.

The resistance of multichannel cyclone with a spiral shell determined during experimental tests on a spiral cyclone with a different number of channels confirms theoretical considerations that the resistance of a cyclone device should increase when the number of channels is increased. These theoretical considerations proved true in all the cases concerned (in the presence of 4, 6 and 8 channels).

The findings of experimental tests allow us to identify shortcomings and further improve the multichannel cyclone structure in order to obtain the best performance in terms of efficiency and aerodynamic characteristics.

\section{4. Conclusions}

1. Average air (gas) flow velocities within multichannel cyclone channels were determined. The average velocity determined in a four-channel spiral cyclone is $5.3 \mathrm{~m} / \mathrm{s}$, six channel cyclone $-4.5 \mathrm{~m} / \mathrm{s}$ and in eight channels $-3.5 \mathrm{~m} / \mathrm{s}$. It is apparent that an increase in the number of channels results in a drop in air (gas) flow velocity: around $18 \%$ in the case of a six-channel spiral cyclone, as high as $51 \%$ in the case of an eight-channel cyclone. This leads to the conclusion that the number of channels in a multichannel spiral cyclone has a direct impact on air (gas) flow velocities in cyclone channels. It has been found that when the number of channels increases air (gas) flow velocity inside the cyclone structure proportionally drops.

2. Based on the results of experimental tests it has been determined that in the case of a higher air (gas) flow rate in the peripheral channel than in the transit one (75/25) a larger air (gas) flow "curtain" forms in the peripheral channel that removes ultra-fine particles from polluted air by filtration and at the same time velocity significantly falls under the impact of increased resistance forces.

3. It has been established during research into aerodynamic resistance of a multichannel cyclone that the highest aerodynamic resistance develops in an eight-channel cyclone structure. The minimum resistance of a multichannel spiralshell cyclone was found in a four-channel spiral cyclone $(238 \mathrm{~Pa})$, while the maximum - in an eight-channel spiral cyclone (310 Pa).

\section{Acknowledgements}

The research has been conducted by implementing project "Application of spiral treatment device with a curvilinear channels for discrete phase treating" (Project No.: MIP-095/2012) of Projects of Research teams of development. Project is jointly funded by the Lithuanian Science Council.

\section{References}

[1] Baltrènas, P.; Pranckevičius, M.; Lietuvninkas, A. 2011. Invstigation and evaluation of carbon dioxide emissions from soil in Neris regional park, Journal of environmental engineering and landscape management 19(2): 115-122.

[2] Baltrènas, P.; Vaitiekūnas, P.; Jakštonienè, I.; Konoverskyte, S. 2012. Study of gas-solid flow in a multichannel cyclone, Journal of environmental engineering and landscape management 20(2): 129-137.

[3] Baltrènas, P.; Zagorskis, A. 2010. Investigation into the air treatment efficiency of biofilters of different structures, Journal of environmental engineering and landscape management 18(1): 23-31. 
[4] Bernardo, S.; Mori, M.; Peres, A. P.; Dionisio, R. P.2006. 3-D Computational fluid Dynamics for gas and gas-particle flows in a cyclone with different inlet section angles, Powder Technology 162(2006): 190-200. http://dx.doi.org/10.1016/j.powtec.2005.11.007

[5] John, W.; Reischl, G. 2012. A Cyclone for Size-Selective Sampling of Ambient Air, Journal of the Air Pollution Control Association 30(8): 872-876. http://dx.doi.org/10.1080/00022470.1980.10465122

[6] Jakštonienė, I.; Serebryanskyy, D.; Vaitiekūnas, P. 2011. Experimental research on the work of centrifugal filter when eliminating solid particles from clinker cooling system, The 8th International Conference „Environmental Engineering “: selected papers, May 19-20, 2011. Vilnius: Technika, 134138 .

[7] Kasiulevičiūtè, A.; Sakalauskienè, S.; Sirtautas, R.; Viršilè, A.; Brazaitytè, A.; Duchovskis, P. 2013. Temperatūros ir drègmės režimo kompleksinis poveikis valgomujų morkų augimui ir fotosintezès pigmentams, 16-osios Lietuvos jaunujų mokslininkų konferencijos "Mokslas - Lietuvos ateitis" teminè konferencija. 2013: 57-63.

[8] Misevičius, A.; Baltrènas, P. 2011. Experimental investigation of biogas production using biodegradable municipal waste, Journal of environmental engineering and landscape management 19(2): 167-177.

[9] Vaitiekūnas, P.; Jakštonienè, I. 2010. Analysis of numerical modeling of turbulence in a conical reverse-flow cyclone, Journal of environmental engineering and landscape management 18(4): 321-328.

[10] Балан, С. А.; Буров, А. А.; Буров, А. И. 2000. Распределение пыли вдоль границы криволинейного потока с замкнутым контуром, Tpyды Одесского политехнического университета 2(11): 56-59.

[11] Буров, А. А.; Карамушко, А. В.; Гамолич, В. Я. 2012. Сравнительная оценка результатов промышленных испытаний циклонов "Сиот” и многоканальных пылеуловителей “Буран”, Прачі Одеського політехнічного університету 1(38): 271-275.

[12] Буров, О. О. 2010. Очищення повітря від пилу в циклонах і буранах, Аграрний вісник причорноморя Вип. (55).

[13] Серебрянский, Д. А. 2004. Повышение еффективности газоочистки тепловых энергетических установок, Oдесca: 149 с.

[14] Стрелец, К. И.; Тананаев, А. В. 2004. Эффективность инерционных фильтров-сепараторов, Материалы 3-й международной научнопрактической конференции "Экономика, экология и общество России в 21 -м столетии". - СПб.: СПбГТУ. 